\title{
A Comprehensive Study on The Accelerated Weathering Properties of Polypropylene-Wood Composites with Non-Metallic Materials of Waste-Printed Circuit Board Powders
}

\author{
Shenghui Tian ${ }^{1,2}{ }^{\oplus}$, Yuanfang Luo ${ }^{2}$, Jizun Chen ${ }^{2}$, Hui He ${ }^{2, *}$, Yong Chen ${ }^{1}$ and Zhang Ling ${ }^{1}$ \\ 1 Chongqing Key Laboratory of Nano-Micro Composite Materials and Devices, School of Metallurgy and \\ Materials Engineering, Chongqing University of Science and Technology, Chongqing 401331, China; \\ tianshenghui@live.cn (S.T.); yongchen998@163.com (Y.C.); 2012024@cqust.edu.cn (Z.L.) \\ 2 School of Materials Science and Engineering, Key Lab of Guangdong Province for High Property and \\ Functional Macromolecular Materials, South China University of Technology, Guangzhou 510640, China; \\ psyfluo@scut.edu.cn (Y.L.); chenjiz@esquel.com (J.C.) \\ * Correspondence: pshuihe@scut.edu.cn; Tel.: +86-18665590301
}

Received: 14 February 2019; Accepted: 12 March 2019; Published: 15 March 2019

check for updates

\begin{abstract}
In this study, non-metallic materials of waste-printed circuit board powders (WPCBP) were successfully used as reinforcing filler to produce polypropylene (PP)-wood composites, and their effect on the weathering properties of PP composites were fully evaluated via oxidation induction time (OIT), attenuated total reflectance Fourier-transform infrared spectroscopy (ATR-FTIR), differential scanning calorimetry, vicat softening point (VST), scanning electron microscopy, and mechanical properties analysis. The OIT analysis confirmed that the anti-thermal oxidative aging properties of PP-wood composites were decreased with the loading of WPCBP. Apart from that, the PP composite, reinforced with $30 \mathrm{wt} . \%$ of WPCBP, exhibited the highest value of active energy, which suggests that it is more sensitive to temperature and oxygen when compared with other PP composites. The mechanical properties analysis revealed that neat PP exhibited the poorest weathering properties after being subjected to UV exposure, and its retention rate of tensile strength and notched impact strength were only $70.6 \%$ and $59.6 \%$, respectively, while WPCBP and wood flour (WF) could efficiently improve the retention rates of the mechanical properties of the PP composites when subjected to UV exposure. The visual appearance of the PP composites after being subjected to UV exposure showed more and smaller cracks with the loading of WPCBP and WF. The ATR-FTIR results revealed that the carbonyl index increased for all the weathered samples, and the more WPCBP was added into the PP composites led to a higher carbonyl index value, which might be due to the multivalent transition metals in WPCBP, which accelerate the photo-oxidation of the PP composites. The VST results show that both WPCBP and WF can effectively enhance the heat deformation resistance of the PP composites that have been subjected to UV exposure.
\end{abstract}

Keywords: polypropylene; non-metallic materials of waste-printed circuit boards powders; wood polymer composites; oxidation induction time; UV resistance

\section{Introduction}

With the rapid development of the electronic information industry, customers frequently update their electronic products, such as mobile phones, computers, televisions, etc. The average effective lifetime of these electronic products has decreased dramatically in recent years, producing a large amount of wasted electric and electronic equipment (WEEE) [1,2]. WEEE is one of the fastest growing 
types of solid waste, and nearly 65.4 million tons of WEEE were generated in 2017 according to the Solving the E-Waste Problem (StEP) initiative, which elevated WEEE to a global environmental issue and a social problem that our society must face [3]. Waste-printed circuit boards (WPCBs) are one of the major components in WEEE, and nearly 1.96 million tons of WPCB were predicted to be generated around the world $[3,4]$.

WPCB could be divided into two parts, i.e., heavy metals and non-metallic materials (WPCBP). Heavy metals account for about 30wt. \% of WPCB, and methods for the recovery of heavy metals have been widely investigated [5]. WPCBP consists of thermosetting resins, glass fibers, and other additives, and several methods have been developed in order to separate and recycle WPCBP, such as chemical, biological, hydrometallurgical, pyrometallurgical, mechanical, plasma, and organic solvent treatment methods [6]. However, there is still a lack of efficient and widely used recycling technologies, and such waste is usually treated by illegal land-filling in some Asian counties (such as Vietnam and China) or incineration due to its complex compositions [6,7]. Extensive studies have evaluated the possibilities of using WPCBP as a reinforcing filler in polymer composites, such as high-density polyethylene (HDPE) [8,9], polypropylene (PP) [10,11], polyvinyl chloride (PVC) [12], polyester [13,14], polyethylene terephthalate (PET) [15], etc. The achievement of high value-added reutilization of WPCBP in polymeric products is an important global issue, and it has drawn great attention in recent years due to economic and environmental concerns [16].

Wood-plastic composites (WPCs), also defined as wood-polymer composites, are made by blending plastic matrixes with agricultural or forestry waste wood fiber (WF), which gives the composite material a wood facade and many mechanical performance advantages $[17,18]$. WPCs have been more widely developed in recent years [19], being abundant, lightweight, formaldehyde-free, and moisture-proof with excellent dimensional stability [20,21], it have been widely used in the construction industry, garden architecture, decorative materials, and the automotive sector [22,23]. Weathering properties are critical for WPCs, because their performances are easily affected during outdoor applications [24], and the weathering properties of WPCs have been a subject of interest for many researchers, because WPCs are often chosen as decorative materials in exterior trim $[25,26]$. Recently, WPCBP has been selected as a reinforcing filler in polyolefin-based WPCs in order to lower material costs [8,27]. However, WPCBP contains residue metals, which cannot be completely recovered during the separating process, and the remaining toxic heavy metals might accelerate the degradation of polymer matrix chains and restrict the material's potential industrial applications [8]. Moreover, there is little existing literature related to the accelerated weathering properties of PP composites reinforced by WPCBP.

PP is one of the most widely used and fastest growing thermoplastics because of its several advantages with regard to cost and performance. However, as an engineering material, PP has the poor weathering properties and is sensitive to heat, light, and oxidation, which limits its industrial applications. Among various factors, photo-oxidation plays an important role in weathering, having remarkable effects on the mechanical and physical properties of materials that have been subjected to UV exposure. In the present work, the influence of WPCBP on the accelerated weathering properties of PP-wood composites were studied, and detailed mechanical, chemical, and thermal properties and structure characterizations were evaluated by oxidation induction time, Fourier- transform infrared spectroscopy, differential scanning calorimetry, vicat softening point, scanning electron microscopy, and mechanical properties analysis before and after UV exposure.

\section{Experimental}

\subsection{Raw Materials}

PP (PPH-T03) with a melt flow index (MFR) of $3.0(+0.5) \mathrm{g} / 10 \mathrm{~min}$ at $200{ }^{\circ} \mathrm{C}$ was used in this investigation, and it was supplied by the Sinopec Maoming Company (Guangdong, China). WPCBP with a mesh of 80, which was provided by Qingyuan Jintian Co. (Guangdong, China), was selected 
for making PP composites. WPCBP was purified according to the reported method, it contained fiber particulate bundles, single-glass fibers, residue multivalent transition metals (such as $\mathrm{Fe}, \mathrm{Cu}$, and $\mathrm{Ni}$ ), and thermosetting powders, and the particle size between 80 and $130 \mathrm{~mm}$ was the most prevalent of WPCBP which amounting to $36.4 \mathrm{wt} \%[8,27]$. Maleated polypropylene (PP-g-MAH) with a grafting rate of $1.0 \%$ was obtained from Kingfa Scientific and Technological Co., Ltd (Guangdong, China). Recovered fir wood flour (WF) with a mesh of 80 was purchased from De Qinglin Wood Flour Co. (Zhejiang, China).

\subsection{Experimental Procedure}

\subsubsection{Preparation of Various PP Composites}

The sample formulations of various PP composites are listed in Table 1. Prior to blending, WPCBP, $\mathrm{WF}$, and PP-g-MAH were dried in a ventilated oven at $80^{\circ} \mathrm{C}$ until a constant weight was reached. The melt mixing was done using a two-roll mill (XK-168, Lina Machinery (Dongguan) Industrial Co., Ltd., Guangdong, China) for $7 \mathrm{~min}$ at $160(+3){ }^{\circ} \mathrm{C}$. Then, the samples were compression molded (XLB-D, Zhejiang Hong Tu Machinery ManufacturingPlant, Jinhua, China) at $180{ }^{\circ} \mathrm{C}$ for $3 \mathrm{~min}$, followed by the cold-press process at room temperature for $7 \mathrm{~min}$ before removing it from the machine. Finally, the samples were cut off for different tests according to the relatedAmerican Society for Testing Material (ASTM) standards.

Table 1. Sample formulations of various polypropylene (PP) composites. WPCBP: waste-printed circuit board powders; WF: wood flour; and PP-g-MAH: maleated polypropylene.

\begin{tabular}{ccccc}
\hline \multirow{2}{*}{ Sample } & \multicolumn{5}{c}{ Composition (wt. \%) } \\
\cline { 2 - 5 } & PP & WPCBP & WF & PP-g-MAH \\
\hline Virgin PP & 100 & 0 & 0 & 0 \\
PP/30WPCBP & 64 & 30 & 0 & 6 \\
PP/20WPCBP/10WF & 64 & 20 & 10 & 6 \\
PP/15WPCBP/15WF & 64 & 15 & 15 & 6 \\
PP/10WPCBP/20WF & 64 & 10 & 20 & 6 \\
PP/30WF & 64 & 0 & 30 & 6 \\
\hline
\end{tabular}

\subsubsection{UV-Accelerated Weathering}

The resistance properties of various PP composites to photo-degradation were tested after a cycle of exposure according to International Standardization Organization (ISO) 4892-1. All the PP samples were put into a UV-340A accelerated weatherometer (GOTECH Testing Machines Co., Ltd. Guangdong, China) the irradiance was fixed at 0.83 , and the processing temperature was set to $50{ }^{\circ} \mathrm{C}$ for 15 days. After that, the samples were conditioned at room temperature for $24 \mathrm{~h}$ before the testing.

\subsection{Testing and Characterization}

\subsubsection{Oxidation Induction Time (OIT)}

The OIT test was performed according to the ISO standard 11357-6:2002 using a differential scanning calorimeter (DSC) (TA Instruments, New Castle, USA) measurement (TA Q20). Firstly, the sample was heated from $30^{\circ} \mathrm{C}$ to the test temperature $\left(190{ }^{\circ} \mathrm{C}, 200{ }^{\circ} \mathrm{C}, 210{ }^{\circ} \mathrm{C}, 220{ }^{\circ} \mathrm{C}\right.$, and $230{ }^{\circ} \mathrm{C}$, respectively) at a heating rate of $20^{\circ} \mathrm{C} / \mathrm{min}$ under nitrogen flow. Then, the sample was held in the test temperature for $5 \mathrm{~min}$. Finally, the $\mathrm{N}_{2}$ flow was switched to oxygen, and the OIT curves were recorded. The OIT values were calculated by TA analysis software (TA Instruments, New Castle, USA). 


\subsubsection{Mechanical Properties}

Tensile tests were conducted with a Zwick/Roell Z010 universal mechanical testing machine (Zwick/Roell, Ulm, Germany) according to ASTM D638 standard, the test speed was fixed at $50 \mathrm{~mm} / \mathrm{min}$, and the tensile strength of PP composites before and after UV exposure were recorded.

Impact testing with specimen dimensions of $80 \mathrm{~mm} \times 12.7 \mathrm{~mm} \times 4 \mathrm{~mm}$ was conducted according to ASTM D256 with a Zwick 5113 impact testing machine (Zwick/Roell, Ulm, Germany). In all cases, 5 specimens were tested, and the average values were reported.

In order to evaluate the UV resistance properties for various PP composites after UV exposure, the mechanical properties retention rates were calculated with the following formula (Equation (1)) in which S stands for variety strength, which includes tensile strength, flexural strength, and notched impact strength. It is generally recognized that composites cannot be used when their mechanical retention rates are less than $50 \%$ after weathering exposure.

$$
\text { Retentionrate }=S_{\text {afterUVexposure }} / S_{\text {untreated samples }} \times 100 \%
$$

\subsubsection{Optical Microscope (OM)}

An optical microscope (OM) of OLYMPUS BX51(Olympus Corporation, Tokyo, Japan) was selected to observe the visual appearance of various PP composites after UV exposure, and the magnification was fixed at 200 times.

\subsubsection{Fourier-Transform Infrared (FTIR)}

The PP composites before and after UV exposure were characterized using an attenuated total reflection (ATR) mode by a MAGBA-IR 760 spectrometer (Nicolet, Waltham, USA), and the wave number was set in the range of $4000-400 \mathrm{~cm}^{-1}$. The carbonyl index (CI) was calculated with the following formula (Equation (2)), in which A represents the peak area, $\mathrm{A}_{2912}$ corresponds to the peak area of $\mathrm{C}-\mathrm{H}$, and $\mathrm{A}_{1715}$ represents the peak area of $\mathrm{C}=\mathrm{O}$ [28].

$$
C I=(A 1715 / A 2912) \times 100 \%
$$

\subsubsection{Differential Scanning Calorimetry (DSC)}

A differential scanning calorimetry (TA instruments DSC Q20) (TA Instruments, New Castle, USA) test was also carried out to study the crystallization and melting behavior of the PP composites before and after UV exposure. The samples were heated at a rate of $10^{\circ} \mathrm{C} / \mathrm{min}$ from $30^{\circ} \mathrm{C}$ to $190{ }^{\circ} \mathrm{C}$ under nitrogen and held for $3 \mathrm{~min}$. Then, the samples were dropped to room temperature at a rate of $10^{\circ} \mathrm{C} / \mathrm{min}$. A total of 3 specimens of each formulation were tested, and the average values were reported.

$T_{p}$ is defined as the crystallization peak temperature, while $T_{m}$ is the melting peak temperature during the first heating cycle and $\mathrm{T}_{\mathrm{m}}-\mathrm{T}_{\mathrm{P}}$ is the degree of super cooling. $\Delta \mathrm{H}_{\mathrm{f}}$ is the melting enthalpy of the first heating cycle. The crystalline fraction $\left(X_{c}\right)$ of various PP composites can be determined from the followed equation (Equation (3)), in which $\mathrm{f}$ is the weight fraction of the filler, $\Delta \mathrm{H}_{\mathrm{f}}$ is the melting enthalpy of the sample, and $\Delta \mathrm{H}_{\mathrm{f}}{ }^{\circ}$ is the theoretical melting enthalpy of $100 \%$ crystalline PP $(209.0 \mathrm{~J} / \mathrm{g})$.

$$
X \mathrm{c}=\left[\Delta H_{f} / \Delta H_{f}^{\circ}(1-f)\right] \times 100 \%
$$

\subsubsection{Vicat Softening Point Analysis}

The Vicat softening temperature (VST) of the PP composites before and after UV exposure was tested by Italian HDT-VICAT Thermal Deformation/VICAT Temperature tester (50 N loaded) (CEAST, Turin, Italy), and the heating rate was $120^{\circ} \mathrm{C} / \mathrm{h}$. The temperature was defined as the VST when the needle was pressed $1 \mathrm{~mm}$ into the sample. 2 specimens of each formulation were tested (the difference is less than $1{ }^{\circ} \mathrm{C}$ ) and the average values were calculated. 


\subsubsection{Scanning Electron Microscopy (SEM)}

A Quanta 200 scanning electron microscopy (SEM) machine [(FEI, Hillaboro, USA) was selected to study the impact fracture morphology of the PP composites (containing the PP matrix, WPCBP, and WF) before and after UV exposure, the SEM settings were listed as follows: high vacuum mode, sputtering $\mathrm{Au}(60 \mathrm{~s})$, working distance of $10 \sim 13 \mathrm{~mm}$, and an accelerating voltage of $10 \mathrm{kV}$.

\section{Results and Discussion}

\subsection{OIT Values}

OIT analysis has been widely used as an effective and easy index to assess the thermal oxidative aging properties of polymer composites [29]. Usually, a higher OIT value indicates that the sample has a better resistance to oxidative degradation $[30,31]$. The resistance to thermal oxidative aging of PP composites with different contents of WPCBP and WF was evaluated by OIT tests, as presented in Figure 1. The OIT value of virgin PP under $190^{\circ} \mathrm{C}$ was $7.1 \mathrm{~min}$, and it decreased dramatically with the increase of WPCBP in the PP composites (the total content of fillers was fixed at $30 \mathrm{wt} . \%$ ). As can be seen clearly, the oxidation of PP/30WPCBP was detected immediately, and its OIT value (which was just $2.7 \mathrm{~min}$ ) is much less than for virgin PP. This might due to the residue multivalent transition metals (such as $\mathrm{Fe}, \mathrm{Cu}$, and $\mathrm{Ni}$ ) in WPCBP, which was proven to have an effect on accelerating the thermal oxidative degradation of PP molecular chains in our previous research [8]. Notably, it the addition of WF could increase the OIT values of the composites, indicating that WF had a positive significant contribution to the anti-thermal oxidative aging properties of the PP composites. This could be attributed to the component of lignin and hindered phenol in WF, which could act as capture agents for the living radicals and then delay the thermal oxidative degradation of the PP composites [18].

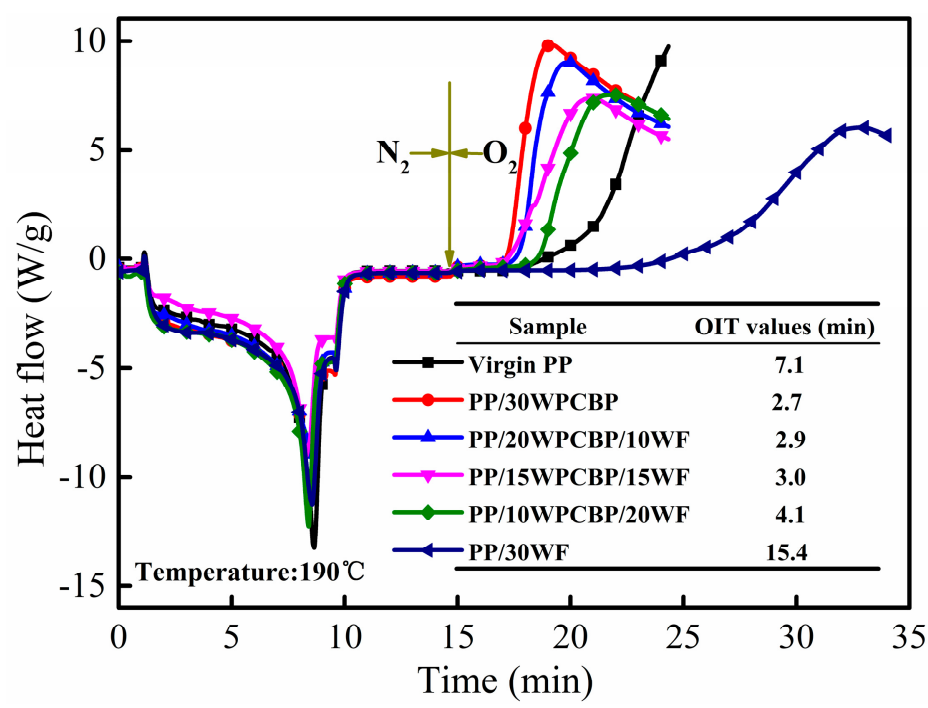

Figure 1. OIT curves and values of various PP composites.

As was known, the OIT values of polymer composites were also influenced by the test temperature. Figure 2 and Table 2 showed the OIT curves and values of PP/30WPCBP (a), PP/20WPCBP/10WF (b) and PP/30WF (c) composites under different test temperatures. It was clearly seen that the OIT curves of three PP samples were left shifted and the OIT values decreased when increasing the test temperature [32]. The related OIT values of the above PP samples under different test temperatures were summarized in Table 2. It also should be noticed that there was a decrease in OIT values with the increase of WPCBP contents under the same test temperature, which could further demonstrate that WPCBP had a negative impact on the thermal oxidative ageing properties of PP composites. 

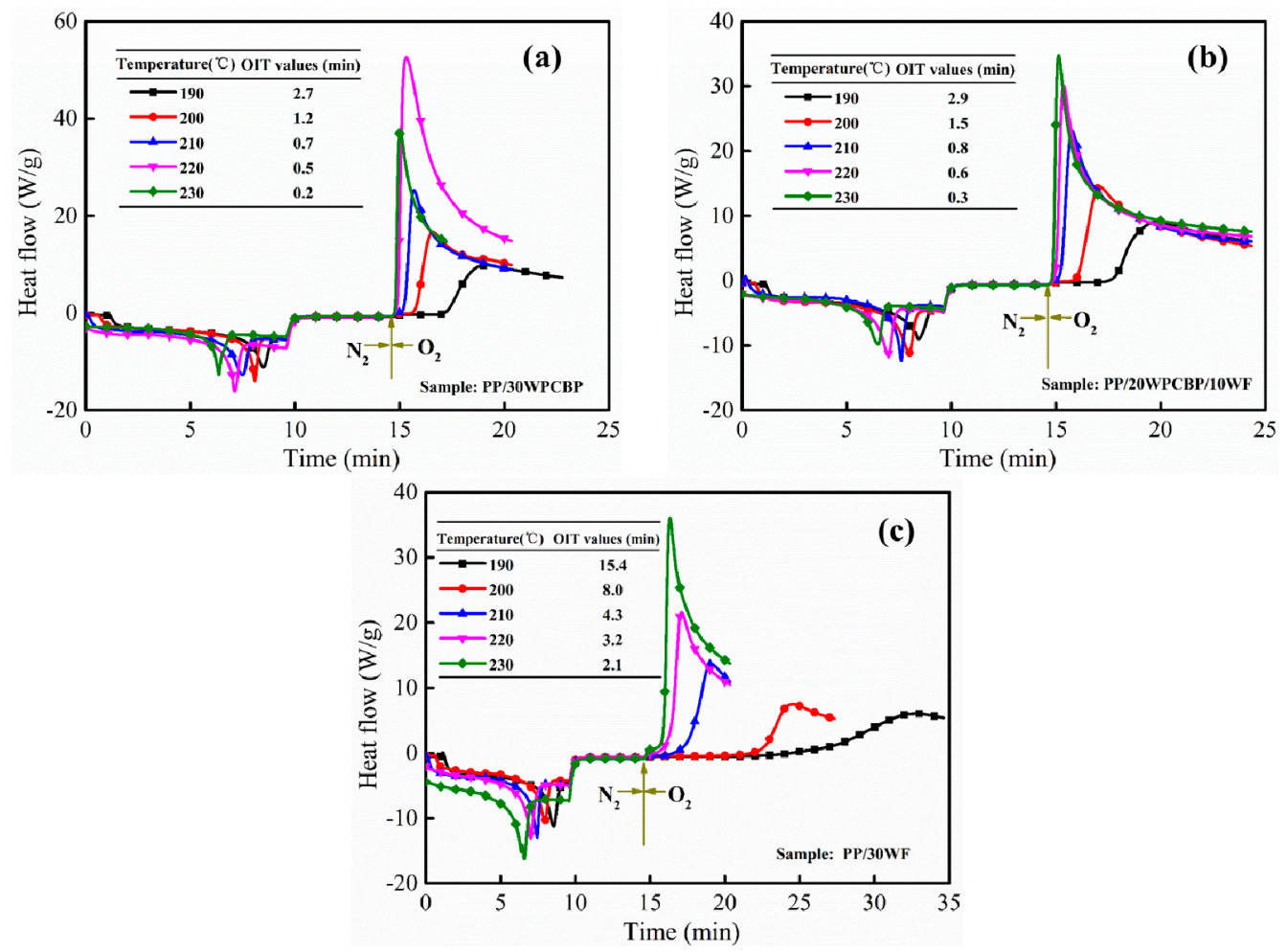

Figure 2. Oxidation induction time (OIT) curves for (a) PP/30WPCBP, (b) PP/20WPCBP/10WF, and (c) $\mathrm{PP} / 30 \mathrm{WF}$ at different testing temperatures.

Table 2. OIT values of various PP composites at different testing temperatures.

\begin{tabular}{cccccc}
\hline \multirow{2}{*}{ Sample } & \multicolumn{5}{c}{ OIT (min) } \\
\cline { 2 - 6 } & $\mathbf{1 9 0}{ }^{\circ} \mathbf{C}$ & $\mathbf{2 0 0}{ }^{\circ} \mathbf{C}$ & $\mathbf{2 1 0}{ }^{\circ} \mathbf{C}$ & $\mathbf{2 2 0}^{\circ} \mathbf{C}$ & $\mathbf{2 3 0}{ }^{\circ} \mathbf{C}$ \\
\hline PP/30WPCBP & 2.7 & 1.2 & 0.7 & 0.5 & 0.2 \\
PP/20WPCBP/10WF & 2.9 & 1.5 & 0.8 & 0.6 & 0.3 \\
PP/30WF & 15.4 & 8.0 & 4.3 & 3.2 & 2.1 \\
\hline
\end{tabular}

The active energy (E) could be calculated by the OIT values from the linear relationship between the logarithm of OIT (Lg OIT) and the inverse of absolute test temperature (1/T) [31]. Usually, E reflects the sensitivity of the thermal oxidative aging of composites to temperature. A higher $\mathrm{E}$ represents poor thermal oxidative resistance for the composite, and its mechanical properties and surface luster are easily affected by the processing temperature [33]. The fitting linear equations of various PP/WPCBP/WF composites are shown in Figure 3, and the related activation energy data are summarized in Table 3. It was found out that the PP/30WPCBP composite had the highest value of E, which indicated that it was more sensitive to temperature than other PP composites, and it was a great negative factor to polymer processing [34,35]. With the increase of WF loading, the activation energy of the PP composite was decreased. This is consistent with the OIT values for the various samples.

Table 3. Activation energy of different PP/WPCBP/WF composites.

\begin{tabular}{ccc}
\hline Sample & $\boldsymbol{L g} \tau=A / T+B$ & Activation Energy E = 2.303RA \\
\hline PP/30WPCBP & $\operatorname{Lg} \tau=5.921 / T-12.38$ & 113.3 \\
$\mathrm{PP} / 20 \mathrm{WPCBP} / 10 \mathrm{WF}$ & $\operatorname{Lg} \tau=5.921 / T-11.21$ & 103.3 \\
$\mathrm{PP} / 30 \mathrm{WF}$ & $\operatorname{Lg} \tau=5.921 / T-9.596$ & 95.2 \\
\hline
\end{tabular}




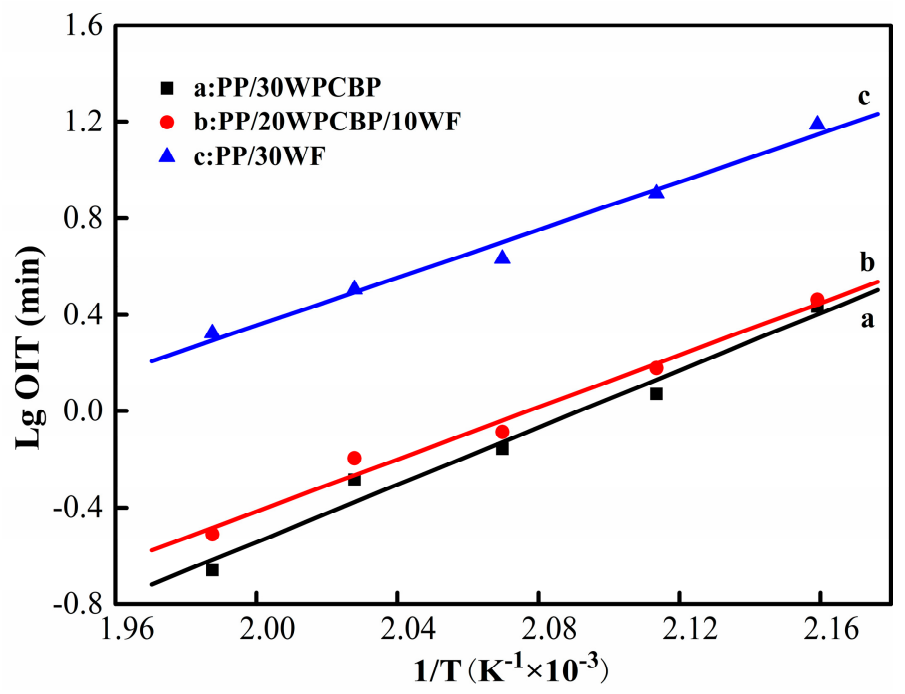

Figure 3. Fitting linear equations of different PP/WPCBP/WF composites.

\subsection{Mechanical Properties}

Figure 4 shows the tensile strength and notched impact strength of virgin PP, PP/30WPCBP, $\mathrm{PP} / 20 \mathrm{WPCBP} / 10 \mathrm{WF}$, and PP/30WF before and after UV exposure. As can be seen, the tensile strength of the PP composites was improved with the loading of WPCBP and WF, while the notched impact strength was increased with the constant loading of WPCBP. Apparently, the PP/30WPCBP composite showed the best mechanical properties among these samples. After 15 days of UV exposure, the tensile strength and notched impact strength for all the PP formulations decreased, and virgin PP showed the largest decreasing amount among them. Interestingly, the tensile strength values and notched impact strength values for all the accelerated PP composites containing WPCBP and WF were higher than virgin PP, and the PP/30WPCBP composite exhibited the highest tensile strength and notched impact strength among these samples.
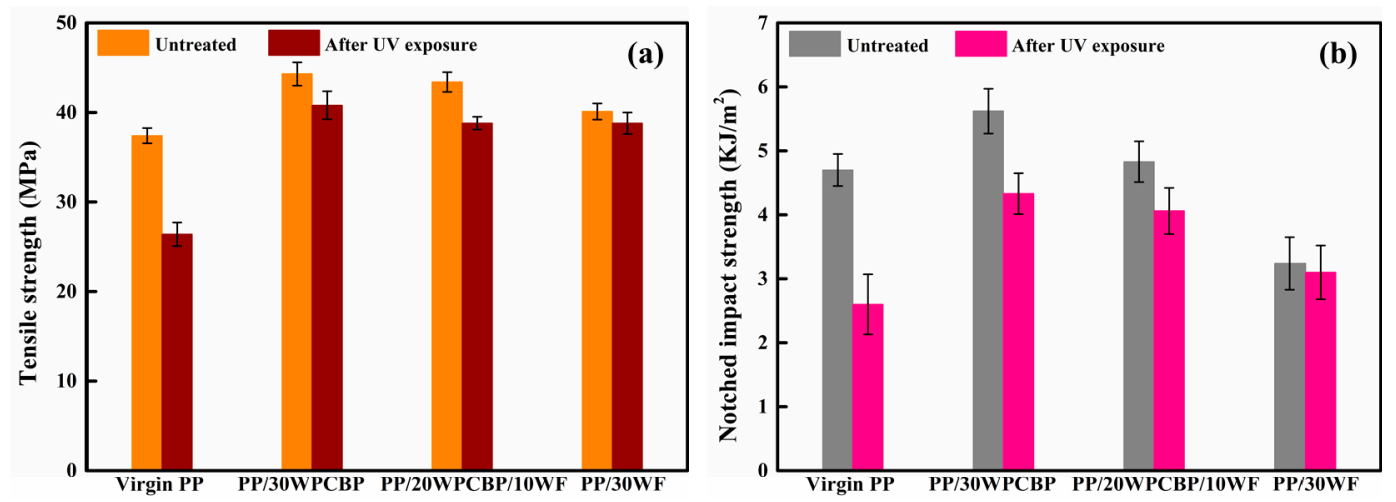

Figure 4. Tensile strength (a) and notched impact strength $(\mathbf{b})$ of various PP composites before and after UV exposure.

The retention rate of tensile strength and notched impact strength of various PP samples after UV exposure are listed in Table 4. As can be seen, virgin PP exhibited the lowest retention rate of mechanical properties, and its retention rate of tensile strength and notched impact strength were only $70.6 \%$ and $59.6 \%$, respectively, indicating that that virgin PP had the poorest UV resistance properties. It can also be observed from Table 4 that all the tensile strength retention rates and notched impact strength of the PP composites were increased with the loading of WPCBP and WF. Specifically, all the tensile strength retention rates of the PP/30WPCBP, PP/20WPCBP/10WF, and PP/30WF samples were higher than $90 \%$, while the notched impact strength retention rate of the PP composites 
increased progressively with the increasing WF loading. These results are within expectations and are in agreement with the results obtained from the OIT values (which are shown in Figures 1 and 3). All these data demonstrated that both WPCBP and WF could effectively improve the mechanical property retention rates of the PP composites after UV exposure, and WF is more pronounced than WPCBP.

Table 4. Retention rate of mechanical properties of various PP composites after UV exposure.

\begin{tabular}{ccc}
\hline \multirow{2}{*}{ Sample } & \multicolumn{2}{c}{ Retention Rate (\%) } \\
\cline { 2 - 3 } & Tensile Strength & Notched Impact Strength \\
\hline Virgin PP & 70.6 & 59.6 \\
PP/30WPCBP & 92.1 & 77.1 \\
PP/20WPCBP/10WF & 90.4 & 84.1 \\
PP/30WF & 96.8 & 95.7 \\
\hline
\end{tabular}

\subsection{Visual Appearance}

Polymers are subject to photo-ageing during UV exposure, and their visual appearance usually changes accordingly [36]. In this study, an optical microscope was used to study the visual appearance of the PP composites after UV exposure, and the obtained visual appearance and digital photographs (magnification: 200 times) are shown in Figures 5 and 6. It is clear that the PP composites made from various formulations responded differently to UV exposure, but obvious cracks were found elsewhere in all the PP composites. The observed deep crisscrossed cracks (which are also known as crazing) demonstrated that the surface structure of virgin PP was destroyed dramatically during UV exposure [37]. It can also be seen from Figure 6 that with the loading of WPCBP and WF, the visual appearance of PP composites after UV exposure showed a tendency to develop increased short crack density and smaller cracks. Apart from that, the depth of the cracks was also decreased. These results further suggest that both WPCBP and WF can effectively improve the UV resistance properties of the PP composites.

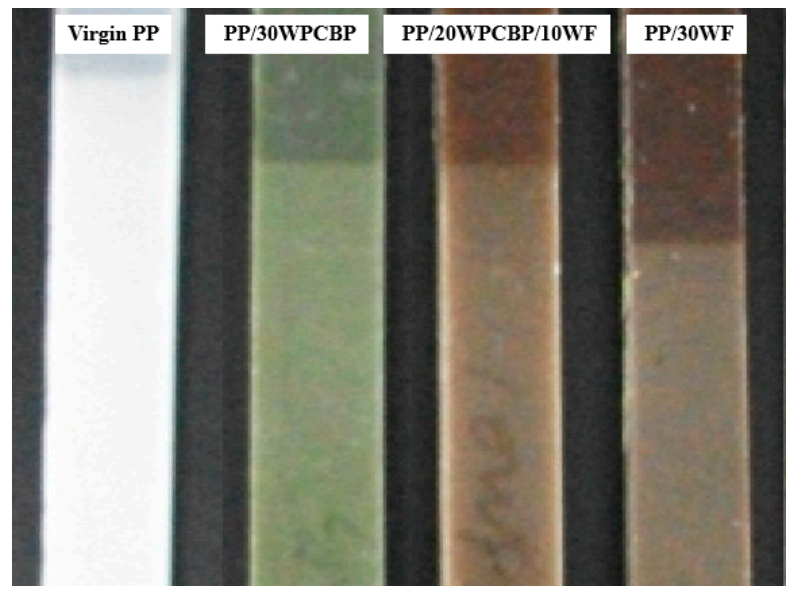

Figure 5. Visual photos of various PP composites after UV exposure.

\subsection{Surface Chemistry}

It is well known that PP has poor weathering properties, as it contains a large amount of $\alpha-\mathrm{H}$, which is unstable and easily oxidized, and it is sensitive to heat, light, and oxidation, which hinders its outdoor applicability [38]. In this study, FTIR spectroscopy was adopted to evaluate the surface chemistry changes of various PP composites before and after UV exposure, and the carbonyl index (CI) calculated from the FTIR test could evaluate the oxidation of the composites. Usually, the more resistant a sample to UV degradation, the lower the CI value. The FTIR spectra of various PP composites (a) before and (b) after UV exposure are shown in Figure 7. 

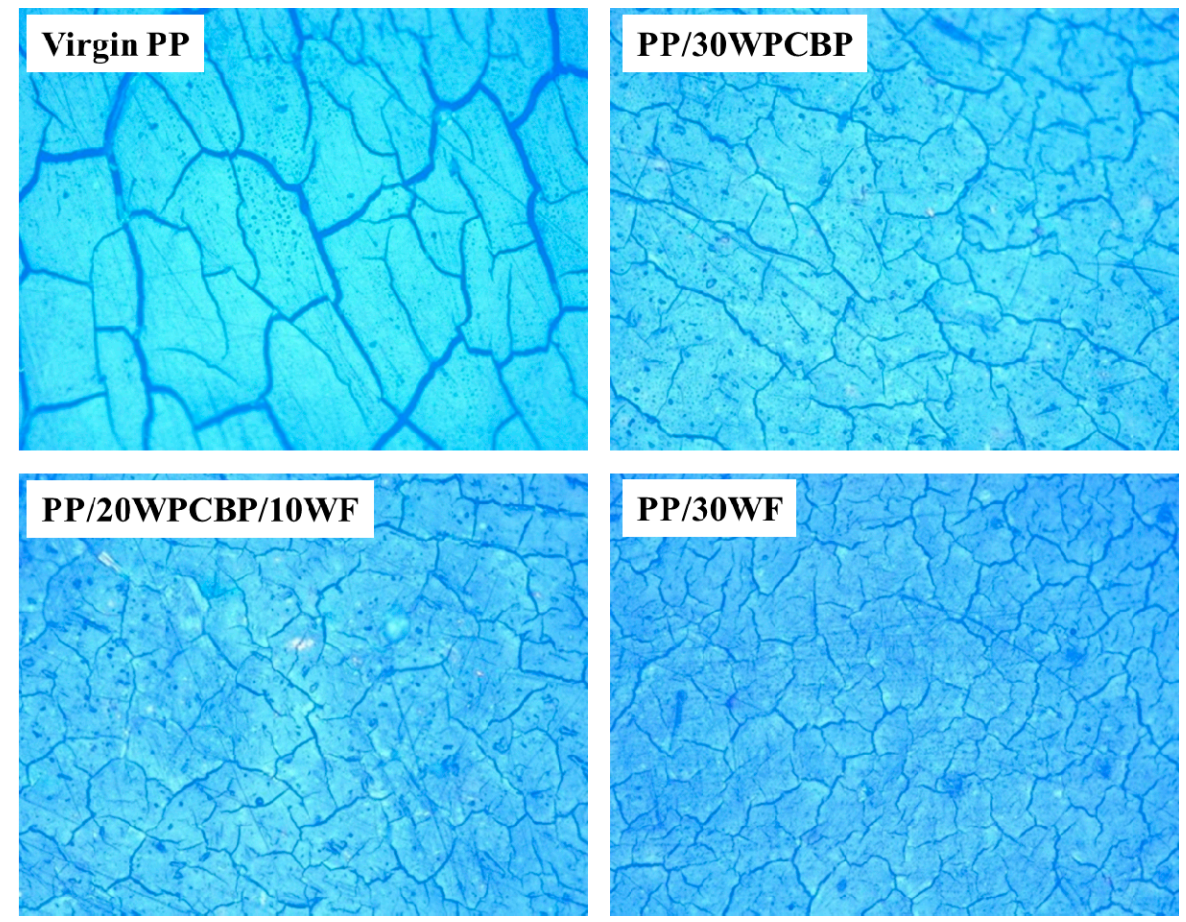

Figure 6. Digital photographs of various PP composites after UV exposure $(\times 200)$.
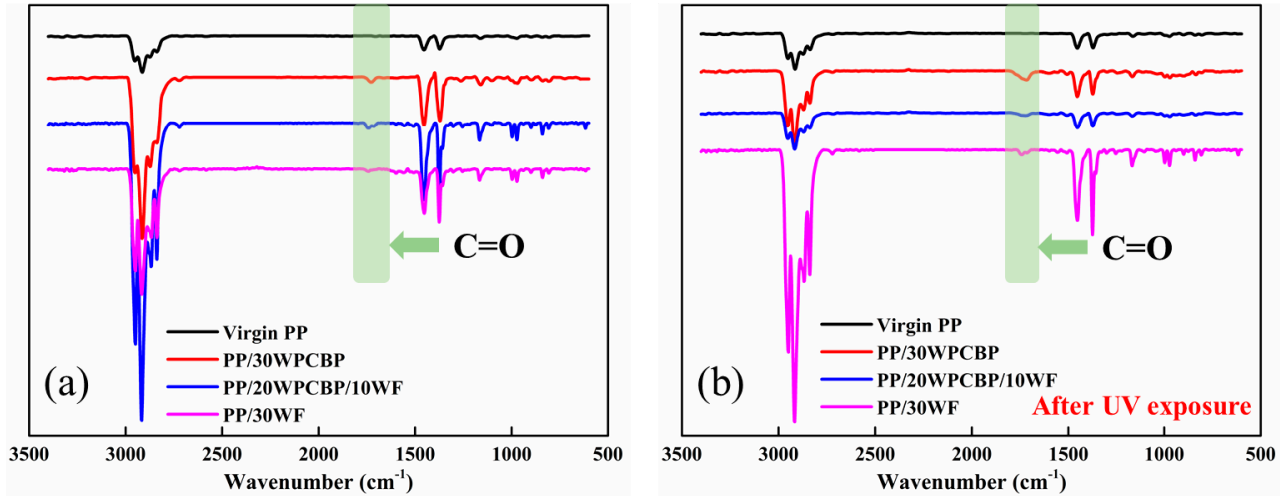

Figure 7. FTIR spectra of various PP composites (a) before and (b) after UV exposure.

It can be observed from Figure $6 a$ that there were no obvious $C=O$ peaks observed at $1715 \mathrm{~cm}^{-1}$ in virgin PP before UV exposure, and the carbonyl groups ( $\mathrm{C}=\mathrm{O}$ peak) were observed with the loading of WPCBP and WF. This might be due to the fact that WPCBP consists of certain amounts of thermosetting plastics, and the lignin in WF is easily oxidized, generating carbonyl groups [39]. Carbonyl groups increased upon UV exposure, showing strong evidence of oxidation. It can be noted from Figure 6 that there is an increase in the intensities of the carbonyl groups at $1715 \mathrm{~cm}^{-1}$ after UV exposure, which indicates the occurrence of photo-oxidation in all the PP composites.

Table 5 summarized the relative carbonyl intensity of various PP samples before and after UV exposure, which were calculated from ATR-FTIR spectra. It can be observed that the PP/30WPCBP sample had the highest carbonyl intensities after UV exposure, indicating that the PP/30WPCBP sample was unstable when compared with other PP composites. Moreover, the observed increase in $\mathrm{CI}$ values after UV exposure also indicated that photo-oxidation occurred in all the PP composites during UV exposure and the more WPCBP added into the samples led to higher CI values. This result should be ascribed to the multivalent transition metals from WPCBP which could accelerate the photo-oxidation of the PP composites. 
Table 5. Relative carbonyl intensity (CI) of various PP samples before and after UV exposure.

\begin{tabular}{ccccccc}
\hline \multirow{2}{*}{ Sample } & \multicolumn{2}{c}{$\mathbf{A}_{\mathbf{2 9 1 2}}$} & \multicolumn{2}{c}{$\mathbf{A}_{\mathbf{1 7 1 5}}$} & \multicolumn{2}{c}{ CI } \\
\cline { 2 - 7 } & Before & After & Before & After & Before & After \\
\hline Virgin PP & 6.76 & 6.44 & 0 & 0.02 & 0 & 0.28 \\
PP/30WPCBP & 27.22 & 13.85 & 0.20 & 1.16 & 0.07 & 8.4 \\
PP/20WPCBP/10WF & 44.16 & 6.79 & 0.38 & 0.32 & 0.86 & 4.68 \\
PP/30WF & 21.02 & 28.16 & 0.13 & 0.34 & 0.62 & 1.2 \\
\hline
\end{tabular}

\subsection{Morphology of the Fractured Surface}

Figure 8 displays SEM photographs of the fractured surface of virgin PP and the reference PP composites after UV exposure (the magnification was fixed at 200 times). It can be seen that the impact fracture of virgin PP after 15 days of UV exposure was smoothed and dimmed, which showed a brittle rupture character. With the loading of WPCBP and WF, it also can be seen from Figure 8 that extensive fiber pull-out voids and debonding were found for the PP/30WPCBP composite after UV exposure, which was due to the degradation and notch-sensitivity of the accelerated composite and resulted in stress concentration more easily. Thus, the notched izod impact strength of the PP composite decreased. With the increase of WF, the pull-out holes decreased, which indicated that WF had better interfacial bonding with the PP matrix after UV exposure. It should be mentioned that the SEM results were within expectations and were also in good agreement with the results obtained from the OIT values and the notched izod impact strength retention rate, which is exhibited in Figure 1 and Table 4, respectively.
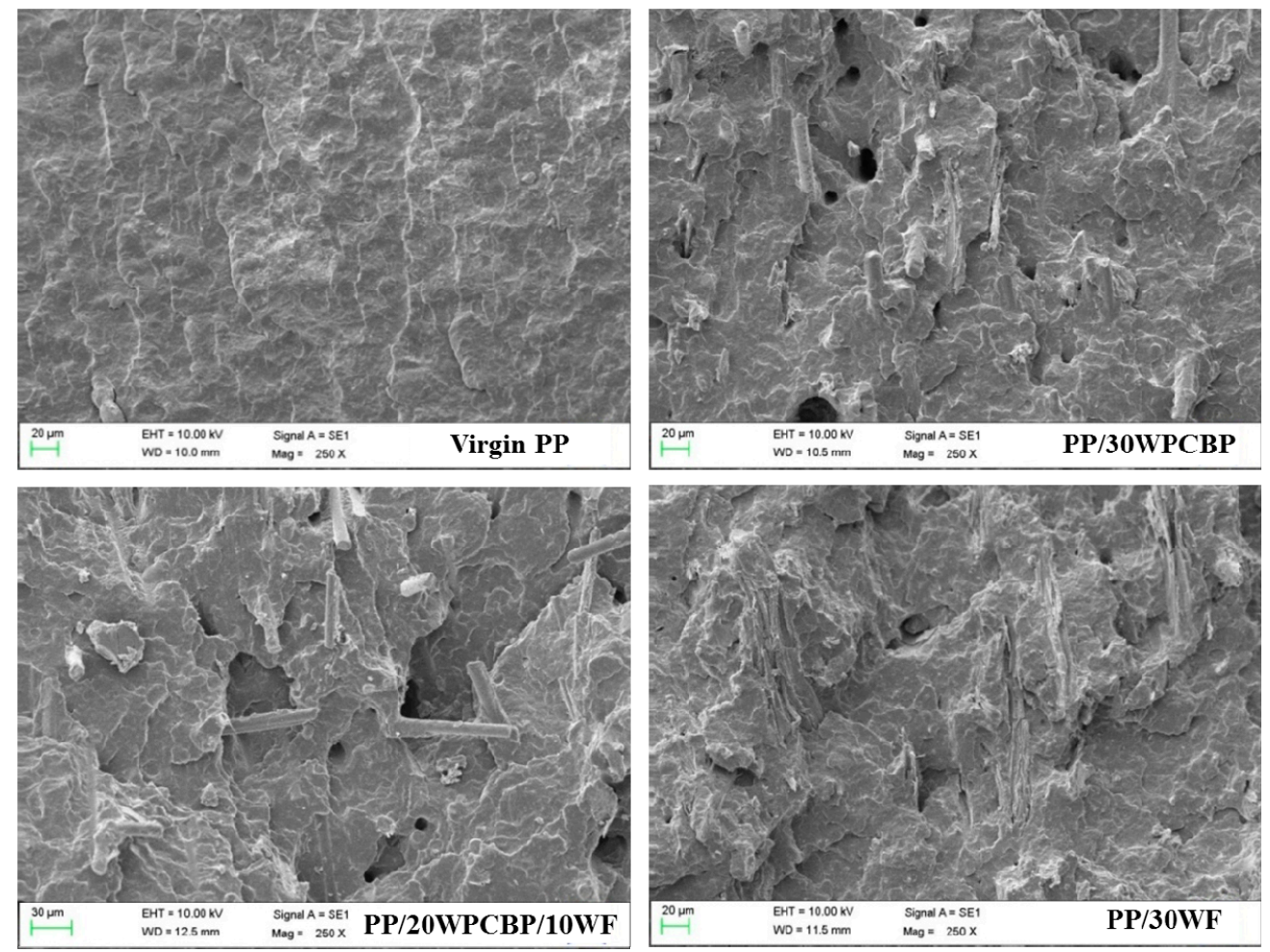

Figure 8. SEM photographs of various PP composites after UV exposure $(\times 250)$.

\subsection{DSC Analysis}

As was known, virgin PP contains significant amounts of large size spherulites, which will lead to high molding shrinkage. In general, the incorporation of fillers can moderately reduce the molding shrinkage ratio of PP composites and improve their dimensional stability. In this study, DSC was 
selected to study the crystallization and melting behavior of various PP composites. Figures 9 and 10 showed the melting curves and crystallization curves of various PP composites (a) before and (b) after UV exposure, respectively. The related data from DSC analysis were calculated and summarized in Table 6.
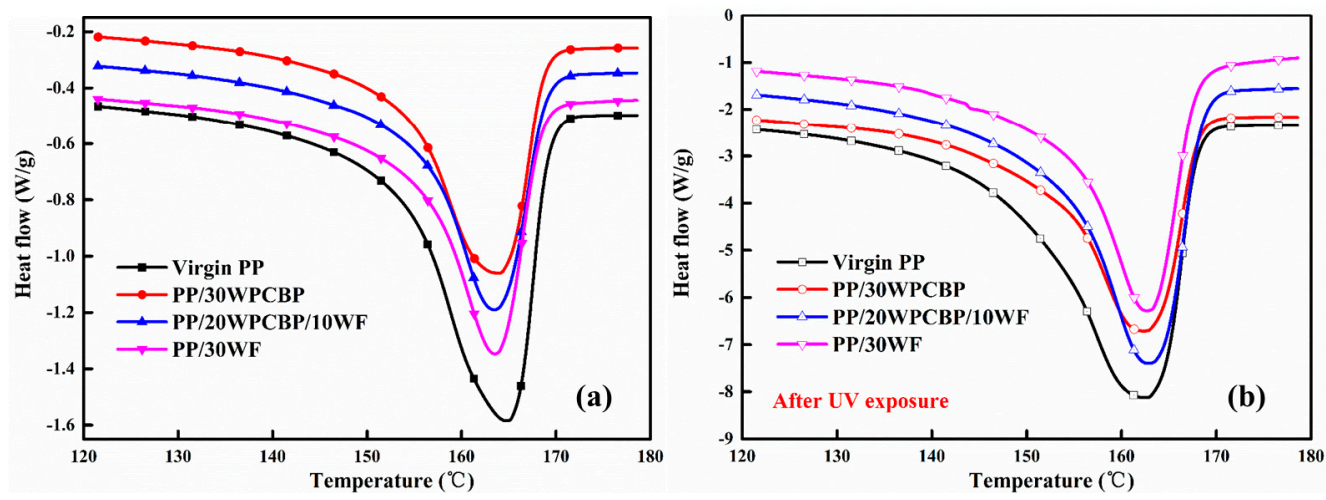

Figure 9. Differential scanning calorimetry (DSC) melting curves of PP composites (a) before and (b) after UV exposure.
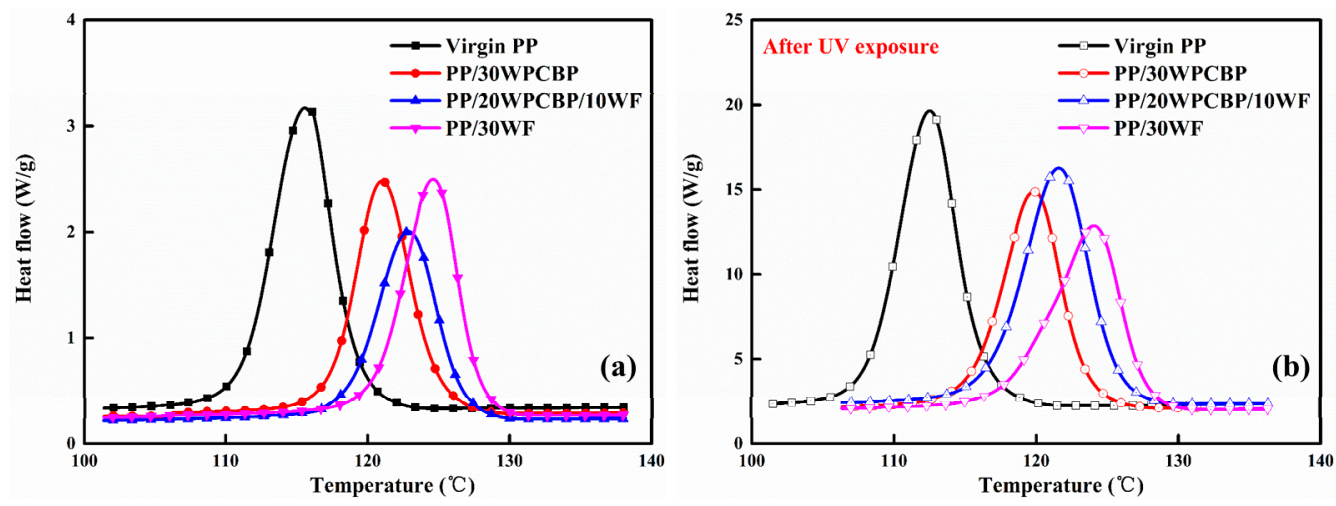

Figure 10. DSC crystallization curves of various PP composites(a) before and (b) after UV exposure.

Table 6. DSC data of various PP composites before and after UV exposure.

\begin{tabular}{ccccccccc}
\hline \multirow{2}{*}{ Sample } & \multicolumn{2}{c}{$\mathbf{T}_{\mathbf{p}}\left({ }^{\circ} \mathbf{C}\right)$} & \multicolumn{2}{c}{$\mathbf{T}_{\mathbf{m}}\left({ }^{\circ} \mathbf{C}\right)$} & \multicolumn{2}{c}{$\mathbf{T}_{\mathbf{m}}-\mathbf{T}_{\mathbf{p}}\left({ }^{\circ} \mathbf{C}\right)$} & \multicolumn{2}{c}{$\mathbf{X}_{\mathbf{c}}(\mathbf{\%})$} \\
\cline { 2 - 9 } & Before & After & Before & After & Before & After & Before & After \\
\hline Virgin PP & 115.6 & 112.5 & 164.7 & 162.6 & 49.1 & 50.1 & 44.9 & 43.8 \\
PP/30WPCBP & 121.0 & 119.3 & 163.8 & 162.4 & 42.8 & 43.1 & 51.3 & 46.4 \\
PP/20WPCBP/10WF & 122.9 & 121.6 & 163.5 & 162.9 & 40.6 & 41.3 & 52.3 & 48.6 \\
PP/30WF & 124.6 & 123.1 & 163.6 & 162.8 & 39 & 39.7 & 55.2 & 53.2 \\
\hline
\end{tabular}

It can be observed that before UV exposure, the crystallization peak temperature $T_{P}$ and the crystalline fraction $X_{c}$ of various PP composites increased upon the incorporation of WPCBP and WF. The PP/30WF composite exhibited better crystallization behaviors than the other PP composites. Its $\mathrm{T}_{\mathrm{P}}$ reached $124.6{ }^{\circ} \mathrm{C}$, and $\mathrm{X}_{\mathrm{C}}$ was $55.2 \%$. This might be due to the heterogeneous nucleation effects of WPCBP and WF. As was known, the crystallization behavior of PP composites is affected by many factors, such as the composition, size of fillers, and distribution, etc. With the loading of WPCBP and WF, different types of heterogeneous nuclei activated, and homogeneous nucleation occurred, which could increase the $X_{c}$ of the ensuring composites. As the average particle size and length of the diameter of WF was smaller than that of WPCBP in the same mesh, WF showed better nucleation effect on PP compared with WPCBP. It can also be seen from Table 6 that the degree of super cooling $\mathrm{T}_{\mathrm{m}}-\mathrm{T}_{\mathrm{P}}$ decreased dramatically upon the incorporation of WF and WPCBP, which was beneficial to 
reduce the molding cycle times of PP composites [40]. In summary, incorporating WPCBP and WF into PP composites could efficiently improve the crystallization properties of the composites.

After UV exposure, all the PP samples showed decreases in TP, Tm, and $X_{c}$ values. This might be due to the fact that the UV aging easily occurred in the non-crystalline region of the PP composites and accelerated the oxidative degradation of the PP molecule chains, which caused the mechanical properties (the tensile strength and notched impact strength) for all the PP formulations to decrease (Figure 4). However, the PP/30WF sample showed a very slight decrease compared to other PP composites, this might due to the fact that it was difficult to cause damage in the crystalline region in brief UV exposure and the WF fillers could absorb parts of the UV light, which could also alleviate the serious degradation of PP macromolecule chains.

\subsection{Vicat Softening Temperature Analysis}

The vicat softening temperature (VST) is defined as the temperature when the needle was pressed $1 \mathrm{~mm}$ into the sample under the application of a load $(50 \mathrm{~N})$, which is an important parameter to evaluate the heat resistance of the composite. Usually, the better the dimensional stability of the sample to the thermal deformation, the higher the VST value.

The VST values of various PP composites before and after UV exposure were investigated, and the results are summarized in Figure 11. Before UV exposure, the VST of virgin PP was $97.8^{\circ} \mathrm{C}$, and it could be observed that the VST of the PP composites increased dramatically with the loading of WPCBP and WF (all above $120^{\circ} \mathrm{C}$ ). This might due to the barrier effect caused by WPCBP and WF which had a load bearing high capability, then avoiding the stress concentration and resulting higher VST values of the composites. It can also be observed from Figure 11 that the VST values for all the PP composites decreased after UV exposure, especially those of virgin PP, which showed the sharpest drop in VST value, which was just $90.2{ }^{\circ} \mathrm{C}$ after UV exposure. It was clearly evident that WPCBP and WF can efficiently enhance the deformation resistance of PP composites

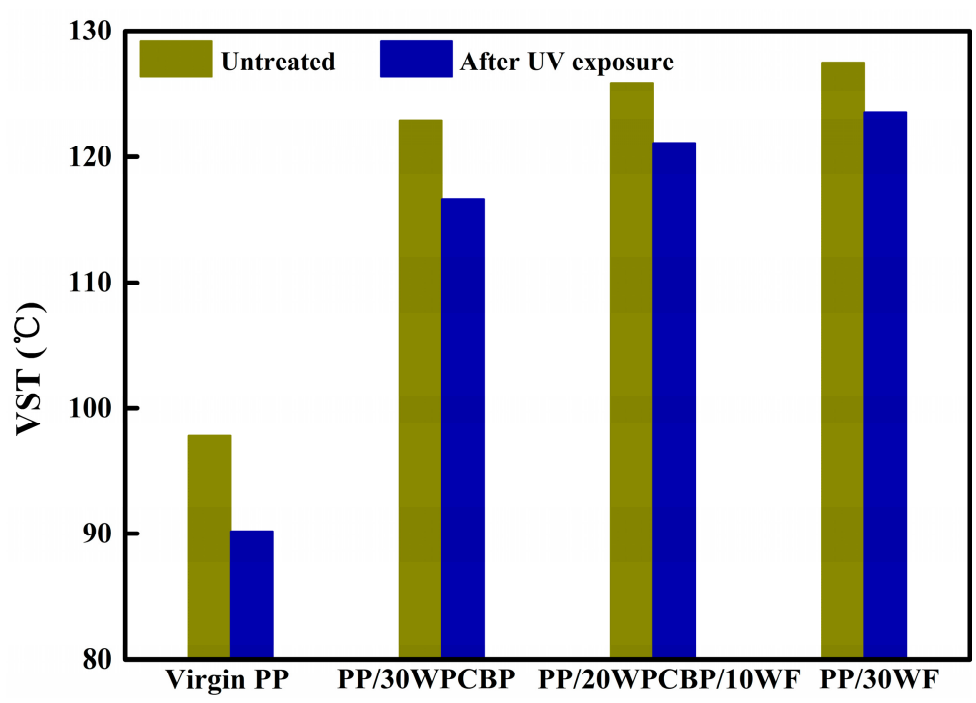

Figure 11. Vicat softening temperature (VST) values of various PP composites before and after UV exposure.

\section{Conclusions}

WPCBP was adopted to reinforce PP-wood composites, and its weathering properties were fully evaluated. OIT analysis confirmed that the anti-thermal oxidative aging properties of PP-wood composites decreased with the increase of WPCBP. Apart from that, the PP/30WPCBP composite had the highest value of active energy, which indicated that it was more sensitive to temperature than other PP composites. Virgin PP, PP/30WPCBP, PP/20WPCBP/10WF, and PP/30WF were weathered up to 
15 days by being subjected to UV exposure. The mechanical properties analysis revealed that virgin PP exhibited the poorest weathering properties, with a tensile strength retention rate and a notched impact strength retention rate that were just $70.6 \%$ and $59.6 \%$, respectively, and the incorporation of WPCBP and WF could remarkably improve the retention rates of the mechanical properties of the PP composites after UV exposure. OM results indicated that the visual appearance of the PP composites after UV exposure showed denser and smaller cracks with the loading of WPCBP and WF. ATR-FTIR results revealed that the carbonyl index increased for all the weathered PP samples; however, the more WPCBP that was added into PP composites led to a higher carbonyl index value, and this should be ascribed to the introduction of multivalent transition metals in WPCBP, which could accelerate the photo-oxidation of the PP composites. VST results suggested that WPCBP and WF can significantly enhance the deformation resistance of the PP composites. SEM analysis indicated that the fracture of virgin PP after UV exposure was smoothed and dimmed, which shown a brittle rupture character, and the fracture appearance changed with the loading of WPCBP and WF.

Author Contributions: S.T., Y.L., H.H. conceived the structure of the manuscript; S.T., J.C. designed and performed most of the experiments, and analyzed all experimental data; Y.C., Z.L. contributed with the discussions of experimental results. All authors contributed in the preparation and review of the manuscript.

Funding: This work was financially supported by the Science and Technology Project of Guangzhou (contract grant number: 201508020090) and the Special Funds for Applied Science and Technology Research and Development of Guangdong Province (contract grant number: 2015B020237004).

Conflicts of Interest: The authors declare no conflicts of interest.

\section{References}

1. Breivik, K.; Armitage, J.M.; Wania, F.; Sweetman, A.J.; Jones, K.C. Tracking the global distribution of Persistent Organic Pollutants accounting for e-waste exports to developing regions. Environ. Sci. Technol. 2015, 50, 798-805. [CrossRef] [PubMed]

2. Cesaro, A.; Marra, A.; Belgiorno, V.; Guida, M. Effectiveness of WEEE mechanical treatment: Separation yields and recovered material toxicity. J. Clean. Prod. 2017, 142, 2656-2662. [CrossRef]

3. Yousef, S.; Tatariants, M.; Tichonovas, M.; Bendikiene, R.; Denafas, G. Recycling of bare waste printed circuit boards as received using an organic solvent technique at a low temperature. J. Clean. Prod. 2018, 187, 780-788. [CrossRef]

4. Verma, H.R.; Singh, K.K.; Mankhand, T.R. Delamination mechanism study of large size waste printed circuit boards by using dimethylacetamide. Waste Manag. 2017, 65, 139-146. [CrossRef] [PubMed]

5. Zlamparet, G.I.; Zeng, X.; Awasthi, A.K.; Li, J. Evaluating waste printed circuit boards recycling: Opportunities and challenges, a mini review. Waste Manag. Res. 2017, 35, 346-356.

6. Zeng, X.; Li, J. Measuring the recyclability of e-waste: an innovative method and its implications. J. Clean. Prod. 2016, 131, 156-162. [CrossRef]

7. Ikhlayel, M. Environmental impacts and benefits of state-of-the-art technologies for E-waste management. Waste Manag. 2017, 68, 458-474. [CrossRef] [PubMed]

8. Tian, S.; He, H.; Yu, P.; Zhou, L.; Luo, Y.; Jia, D. Sustainable utilization of waste printed circuit boards powders in HDPE-wood composites: Synergistic effects of multicomponents on structure and properties. J. Clean. Prod. 2017, 164, 840-847. [CrossRef]

9. Yang, S.; Bai, S.; Wang, Q. Morphology, mechanical and thermal oxidative aging properties of HDPE composites reinforced by nonmetals recycled from waste printed circuit boards. Waste Manag. 2016, 57, 168-175. [CrossRef] [PubMed]

10. Kumar, A.; Choudhary, V.; Khanna, R.; Tripathi, S.N.; Ikram-Ul-Haq, M.; Sahajwalla, V. Structural, thermal, morphological and dynamic mechanical characteristics of waste-reinforced polypropylene composites: A novel approach for recycling electronic waste. J. Appl. Polym. Sci. 2016, 133, 43389. [CrossRef]

11. Hadi, P.; Ning, C.; Ouyang, W.; Xu, M.; Lin, C.S.K.; McKay, G. Toward environmentally-benign utilization of nonmetallic fraction of waste printed circuit boards as modifier and precursor. Waste Manag. 2015, 35, 236-246. [CrossRef] [PubMed] 
12. Pan, Y.-T.; Wang, D.-Y. Fabrication of low-fire-hazard flexible poly (vinyl chloride) via reutilization of heavy metal biosorbents. J. Hazard. Mater. 2017, 339, 143-153. [CrossRef] [PubMed]

13. Hu, D.; Jia, Z.; Li, J.; Zhong, B.; Fu, W.; Luo, Y. Characterization of Waste Printed Circuit Boards Nonmetals and its Reutilization as Reinforcing Filler in Unsaturated Polyester Resin. J. Polym. Environ. 2017, 26, 1311-1319. [CrossRef]

14. Hu, D.; Jia, Z.; Zhong, B.; Lin, J.; Liu, M.; Luo, Y.; Jia, D. Method for improving the mechanical performance and thermal stability of unsaturated polyester resin/waste-printed circuit board nonmetals composites via isocyanate chemistry. J. Appl. Polym. Sci. 2017, 134, 45129. [CrossRef]

15. Kovačević, T.; Rusmirović, J.; Tomić, N.; Marinović-Cincović, M.; Kamberović, Željko; Tomić, M.; Marinković, A.; Kovaevi, T.; Rusmirovi, J.; Tomi, N.; et al. New composites based on waste PET and non-metallic fraction from waste printed circuit boards: Mechanical and thermal properties. Compos. Part $B$ Eng. 2017, 127, 1-14. [CrossRef]

16. Yu, D.; Duan, H.; Song, Q.; Liu, Y.; Li, Y.; Li, J.; Shen, W.; Luo, J.; Wang, J. Characterization of brominated flame retardants from e-waste components in China. Waste Manag. 2017, 68, 498-507. [CrossRef] [PubMed]

17. Bin Bahari, S.A. Wood-polymer Composites. J. Clean. Prod. 2016, 110, 194. [CrossRef]

18. Quiroga, A.; Marzocchi, V.; Rintoul, I. Influence of wood treatments on mechanical properties of wood-cement composites and of Populus Euroamericana wood fibers. Compos. Part B Eng. 2016, 84, 25-32. [CrossRef]

19. Torres-Giner, S.; Montanes, N.; Fenollar, O.; García-Sanoguera, D.; Balart, R. Development and optimization of renewable vinyl plastisol/wood flour composites exposed to ultraviolet radiation. Mater. Des. 2016, 108, 648-658. [CrossRef]

20. Sommerhuber, P.F.; Wenker, J.L.; Rüter, S.; Krause, A. Life cycle assessment of wood-plastic composites: Analysing alternative materials and identifying an environmental sound end-of-life option. Resour. Conserv. Recycl. 2017, 117 Pt B, 235-248. [CrossRef]

21. Chen, H.; Tian, S.; He, H. Mechanical, flammability, and thermal properties of polyvinyl chloride-wood composites with carbide slag. Polym. Compos. 2015, 38, 2898-2906.

22. Teuber, L.; Osburg, V.-S.; Toporowski, W.; Militz, H.; Krause, A. Wood polymer composites and their contribution to cascading utilisation. J. Clean. Prod. 2016, 110, 9-15. [CrossRef]

23. Muniyandi, S.K.; Sohaili, J.; Hassan, A. Accelerated weathering properties of compatibilized composites made from recycled HDPE and nonmetallic printed circuit board waste. J. Appl. Polym. Sci. 2015, 133, 43110-43121. [CrossRef]

24. Schirp, A.; Su, S. Effectiveness of pre-treated wood particles and halogen-free flame retardants used in wood-plastic composites. Polym. Degrad. Stab. 2016, 126, 81-92. [CrossRef]

25. Väntsi, O.; Kärki, T. Environmental assessment of recycled mineral wool and polypropylene utilized in wood polymer composites. Resour. Conserv. Recycl. 2015, 104, 38-48. [CrossRef]

26. Bhat, I.-U.-H.; Khalil, H.A.; Awang, K.B.; Bakare, I.; Issam, A. Effect of weathering on physical, mechanical and morphological properties of chemically modified wood materials. Mater. Des. 2010, 31, 4363-4368. [CrossRef]

27. Tatariants, M.; Yousef, S.; Denafas, G.; Bendikiene, R. Separation and purification of metal and fiberglass extracted from waste printed circuit boards using milling and dissolution techniques. Environ. Prog. Sustain. Energy 2018, 37, 2082-2092. [CrossRef]

28. Azuma, Y.; Takeda, H.; Watanabe, S.; Nakatani, H. Outdoor and accelerated weathering tests for polypropylene and polypropylene/talc composites: A comparative study of their weathering behavior. Polym. Degrad. Stab. 2009, 94, 2267-2274. [CrossRef]

29. Bu, J.; Huang, X.; Li, S.; Jiang, P. Significantly enhancing the thermal oxidative stability while remaining the excellent electrical insulating property of low density polyethylene by addition of antioxidant functionalized graphene oxide. Carbon 2016, 106, 218-227. [CrossRef]

30. Beer, S.; Teasdale, I.; Brueggemann, O. Macromolecular antioxidants via thiol-ene polyaddition and their synergistic effects. Polym. Degrad. Stab. 2014, 110, 336-343. [CrossRef]

31. Gijsman, P.; Sampers, J. Oxygen uptake measurements to identify the cause of unexpected differences between accelerated and outdoor weathering. Angew. Makromol. Chem. 1998, 261-262, 77-82. [CrossRef] 
32. Essabir, H.; Bensalah, M.O.; Rodrigue, D.; Bouhfid, R.; Qaiss, A.E.K. A comparison between bio- and mineral calcium carbonate on the properties of polypropylene composites. Constr. Build. Mater. 2017, 134, 549-555. [CrossRef]

33. Gao, X.; Hu, G.; Qian, Z.; Ding, Y.; Zhang, S.; Wang, D.; Yang, M. Immobilization of antioxidant on nanosilica and the antioxidative behavior in low density polyethylene. Polymer 2007, 48, 7309-7315. [CrossRef]

34. Kallakas, H.; Poltimäe, T.; Süld, T.-M.; Kers, J.; Krumme, A. The influence of accelerated weathering on the mechanical and physical properties of wood-plastic composites. Proc. Est. Acad. Sci. 2015, 64, 94-104. [CrossRef]

35. Aldajah, S.; Al-Omari, A.; Biddah, A. Accelerated weathering effects on the mechanical and surface properties of CFRP composites. Mater. Des. 2009, 30, 833-837. [CrossRef]

36. Yang, X.; Ding, X. Prediction of outdoor weathering performance of polypropylene filaments by accelerated weathering tests. Geotext. Geomembr. 2006, 24, 103-109. [CrossRef]

37. Stark, N.M.; Matuana, L.M. Characterization of weathered wood-plastic composite surfaces using FTIR spectroscopy, contact angle, and XPS. Polym. Degrad. Stab. 2007, 92, 1883-1890. [CrossRef]

38. Pandey, K.; Pitman, A. FTIR studies of the changes in wood chemistry following decay by brown-rot and white-rot fungi. Int. Biodeterior. Biodegrad. 2003, 52, 151-160. [CrossRef]

39. Muasher, M.; Sain, M. The efficacy of photostabilizers on the color change of wood filled plastic composites. Polym. Degrad. Stab. 2006, 91, 1156-1165. [CrossRef]

40. Gulmine, J.; Janissek, P.; Heise, H.; Akcelrud, L. Degradation profile of polyethylene after artificial accelerated weathering. Polym. Degrad. Stab. 2003, 79, 385-397. [CrossRef]

(C) 2019 by the authors. Licensee MDPI, Basel, Switzerland. This article is an open access article distributed under the terms and conditions of the Creative Commons Attribution (CC BY) license (http:/ / creativecommons.org/licenses/by/4.0/). 